\title{
UCRL-CONF-212186
}

LAW RENCE LIVERMORE N A T IO N A L LABORATORY

\section{A Compact High-Brightness Heavy-Ion Injector}

G. A. Westenskow, D. P. Grote, E. Halaxa, J. W. Kwan, F. Bieniosek

May 12, 2005

Particle Accelerator Conference 2005

Knoxville, TN, United States

May 17, 2005 through May 21, 2005 
This document was prepared as an account of work sponsored by an agency of the United States Government. Neither the United States Government nor the University of California nor any of their employees, makes any warranty, express or implied, or assumes any legal liability or responsibility for the accuracy, completeness, or usefulness of any information, apparatus, product, or process disclosed, or represents that its use would not infringe privately owned rights. Reference herein to any specific commercial product, process, or service by trade name, trademark, manufacturer, or otherwise, does not necessarily constitute or imply its endorsement, recommendation, or favoring by the United States Government or the University of California. The views and opinions of authors expressed herein do not necessarily state or reflect those of the United States Government or the University of California, and shall not be used for advertising or product endorsement purposes. 


\title{
A COMPACT HIGH-BRIGHTNESS HEAVY-ION INJECTOR *
}

\author{
G.A. Westenskow", D.P. Grote, E. Halaxa, LLNL, Livermore, CA, 94551, U.S.A. \\ J.W. Kwan, F. Bieniosek, LBNL, Berkeley, CA, 94720, U.S.A.
}

\begin{abstract}
To provide a compact high-brightness heavy-ion beam source for Heavy Ion Fusion (HIF) accelerators, we have been experimenting with merging multi-beamlets in an injector which uses an RF plasma source. In an $80-\mathrm{kV} 20$ microsecond experiment, the RF plasma source has produced up to $5 \mathrm{~mA}$ of $\mathrm{Ar}^{+}$in a single beamlet. An extraction current density of $100 \mathrm{~mA} / \mathrm{cm}^{2}$ was achieved, and the thermal temperature of the ions was below $1 \mathrm{eV}$. We have tested at full voltage gradient the first 4 gaps of an injector design. Einzel lens were used to focus the beamlets while reducing the beamlet to beamlet space charge interaction. We were able to reach greater than 100 $\mathrm{kV} / \mathrm{cm}$ in the first four gaps. We also performed experiments on a converging 119 multi-beamlet source. Although the source has the same optics as a full 1.6 MV injector system, these test were carried out at $400 \mathrm{kV}$ due to the test stand HV limit. We have measured the beam's emittance after the beamlets are merged and passed through an electrostatic quadrupole (ESQ). Our goal is to confirm the emittance growth and to demonstrate the technical feasibility of building a driver-scale HIF injector.
\end{abstract}

\section{BACKGROUND}

Following a proposal that the usual limits on brightness for compact ion-beam sources used in Heavy Ion Fusion can be circumvented by using a multi-beamlet injector ${ }^{1}$, we have performed an experimental program to examine practical issues. The final source envisioned will start with $\sim 200$ 5-mA beamlets across a 100-kV gap. The beamlets will be focused by Einzel Lens while their energy is increased to about $1.2 \mathrm{MeV}$. The beamlets are then merged to produce a 1-A beam with a normalized $4 *$ rms emittance of about $1 \pi$-mm-mrad at $1.6 \mathrm{MeV}$.

Beyond providing a low-temperature source that can provide ion emission densities of $\sim 100 \mathrm{~mA} / \mathrm{cm}^{2}$, the main physics issues involved in the multi-beamlet approach are emittance growth and envelope matching in the merging process. Computer simulations show that if the initial emittance of the beamlets is small, then it only contributes weakly to the final emittance of the merged beam ${ }^{1}$.

\section{STUDYING INDIVIDUAL BEAMLETS}

We are using an rf plasma source to produce an argon ion beamlets. The plasma chamber has $26-\mathrm{cm}$ inner

\footnotetext{
* This work has been performed under the auspices of the US DOE by UC-LBNL under contract DE-AC0376SF00098 and by UC-LLNL under contract W-7405ENG-48, for the Heavy Ion Fusion Virtual National Laboratory \# westenskow1@llnl.gov
}

diameter with multicusp permanent magnets to confine plasma. RF power (13 MHz) is applied to the source via a 2-turn, 11-cm diameter antenna inside the chamber for producing beam pulses of $20 \mu \mathrm{s}$ at up to $10 \mathrm{~Hz}$. We have shown that we can extract $100 \mathrm{~mA} / \mathrm{cm}^{2}$ from the chamber. Optimum performance at $80 \mathrm{kV}$ was achieved with $\sim 2$ mTorr gas in the plasma chamber using $22 \mathrm{~kW}$ of rf drive power The lowest emittance (optics) was achieved when the beamlet current was slightly below the peak current value. Current density was found to increase with RF power as long as there was sufficient extraction voltage. At $80 \mathrm{kV}$, we have reached our goal of producing 100 $\mathrm{mA} / \mathrm{cm}^{2}$ of $\mathrm{Ar}^{+}$ions (i.e. $4.9 \mathrm{~mA}$ per beamlet). For operation with $10 \mathrm{~kW}$ of drive powers we estimated that less than $5 \%$ of the extracted ions were in the $\mathrm{Ar}^{++}$state. Additional details about the rf plasma source have been published ${ }^{2,3,4}$.

\section{MULTI-BEAMLET EXPERIMENTS}

\section{Full Gradient Experiment}

We have tested a 61-beamlet extraction array using a series of Einzel lens ${ }^{4}$. The source apertures were $2.2 \mathrm{~mm}$ in diameter while all the other electrodes had $4.0 \mathrm{~mm}$ diameter holes. The current per beamlet is $3.8 \mathrm{~mA}$ at an extraction current density of $100 \mathrm{~mA} / \mathrm{cm}^{2}$. There are 61 beamlets for a total current of $232 \mathrm{~mA}$.

One of our goals was to test the high gradient insulators which were used to assemble the electrode plates. When tested individually, each would hold $80 \mathrm{kV}$ DC without beam. The insulators were either $4.27 \mathrm{~cm}$ or $2.13 \mathrm{~cm}$ in length. A conservative working voltage is about $30 \mathrm{kV} / \mathrm{cm}$ for a $20-\mu$ sec pulse in the gap environment. Achieving these gradients required conditioning of the surfaces.

The Full-Gradient Experiment was designed to test the limit of high current density extraction in the working environment of the RF Plasma source. The dimensions and electric fields are typical of what we would like to use in a driver scale injector. Since we are limited to about $400-\mathrm{kV}$ of pulsed voltage, only the first 5 gaps of a full system could be tested. To reduce the cost we did not use curved plates. The highest vacuum electric field gradient occurred between the $2^{\text {nd }}$ plate and the $3^{\text {th }}$ plate, and was $100 \mathrm{kV} / \mathrm{cm}$ on axis for a $1.2 \mathrm{~cm}$ gap. Fields at the edge of the holes are expected to be about $120 \mathrm{kV} / \mathrm{cm}$ for this gap.

\section{Merging beamlets into an ESQ \\ For a proof-of-principle test of the merging process we have designed an experiment at full dimensions, but which will operate at one-quarter the voltage of a drive scaled injector. Since all the voltages in this electrostatic}




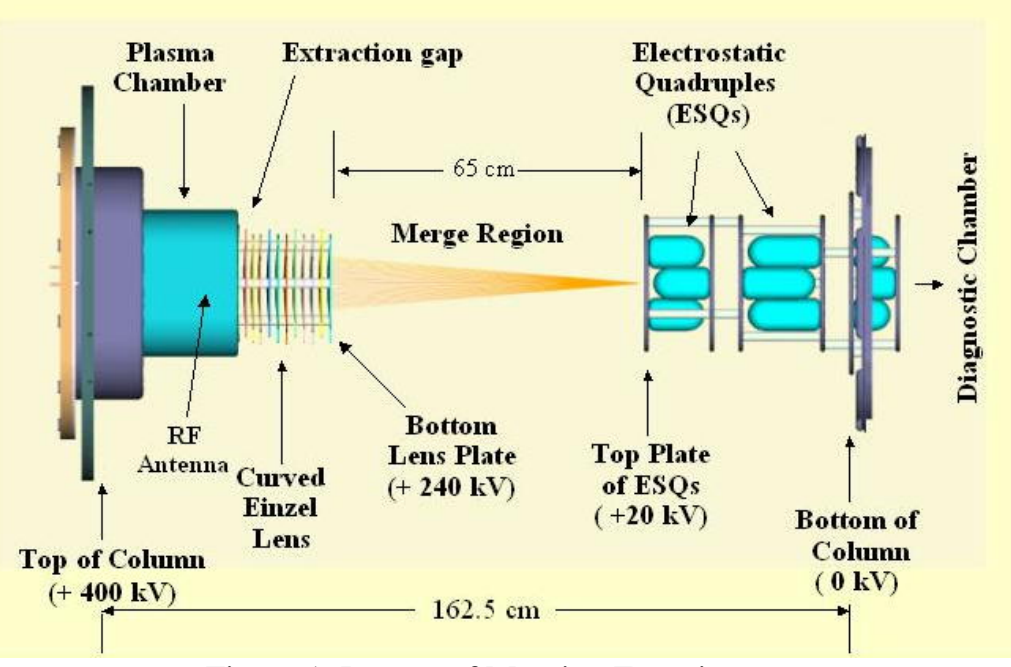

Figure 1. Layout of Merging Experiment.

system are reduced by the same factor, and the current density is scaled according to the " $3 / 2$ " space charge limited condition, the beam optics of merging remains unchanged. A layout is shown in Fig. 1. There was an extraction plate plus 10 lens plates in the experiment. Figure 2 shows the lens assembly mounted in the column and Figure 3 shows a typical curved plate in the lens assembly with 119 apertures. Because the voltages between plates was reduced by a factor of four, we did not need reentrant cups, as in the Full-Gradient Experiment. We used HGI directly between the plates to hold the assemble together and provide alignment.

The emittance growth (normalized to a constant beam current) is minimized when the beamlet energy is high (at the time of merging), the number of beamlets is large, and the beamlets are close to each others. The final emittance depends on the initial beamlet convergent angle and

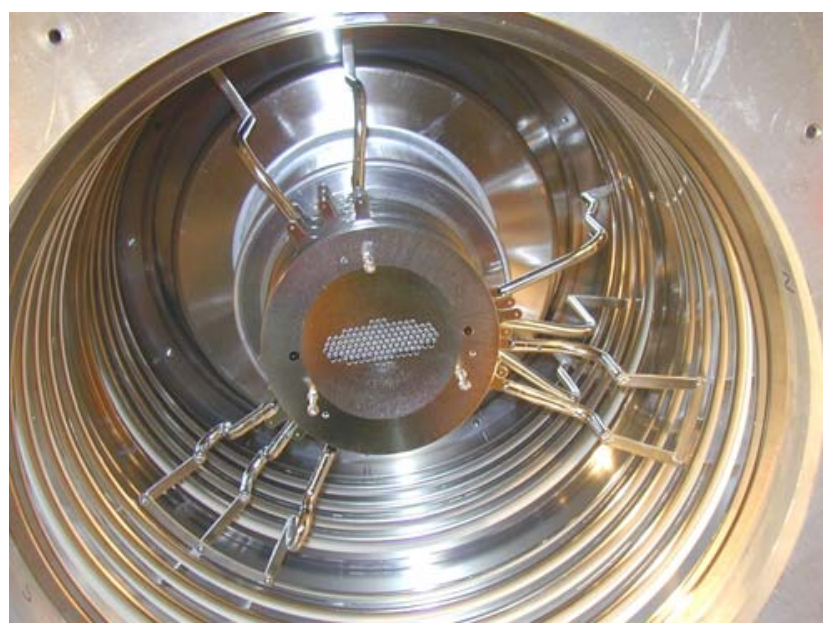

Figure 2 . Einzel Lens Assemble installed in the top of the column (without the field shield installed). weakly on the ion temperature ${ }^{1}$. Figure 4 shows the evolution of beamlets in configuration space. The $\mathrm{x}$ and $\mathrm{y}$ rms emittance was found to initially rise to different values because of the elliptical shape but later came to an equilibrium value (average between $\mathrm{x}$ and $\mathrm{y}$ emittance) in about $10 \mathrm{~m}$ distance.

Figure 5 shows an emittance diagram (constructed from optical images produced by the ions passing through a slit) at $10 \mathrm{~cm}$ beyond the end of the ESQs. Figure 6 shows a comparison of predicted emittance and the measured emittances. Signal noise made it difficult to find the edge of the phase space in the experiments. The optical emittance scans used a 90\% amplitude cutoff. The slit scanner emittances fit the emittance vs. cutoff curve, and projected back to $100 \%$ level. The simulations line is the $4 *$ rms emittance taken for $90 \%$ of the ions.

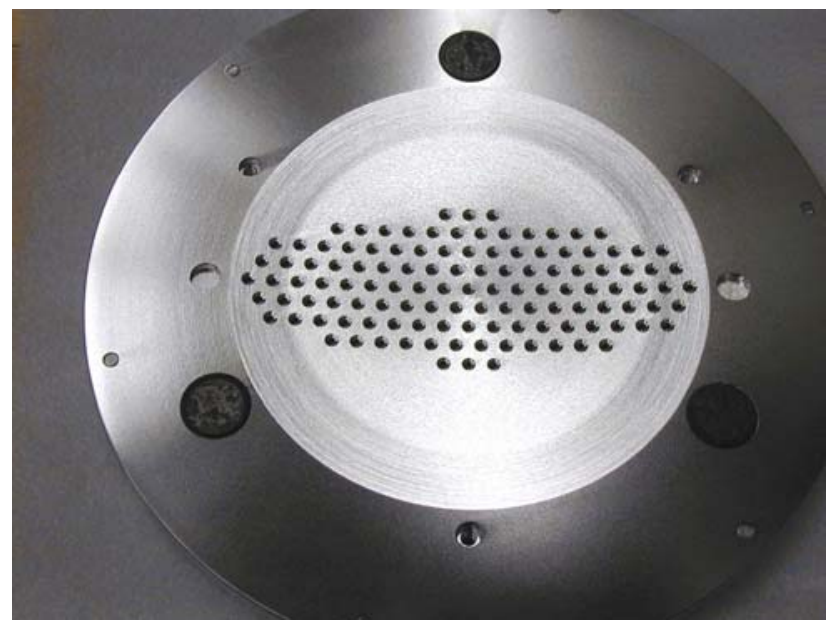

Figure 3. One of the Lens Plates with 119 beamlet holes. The radius of curvature is about $60 \mathrm{~cm}$. 


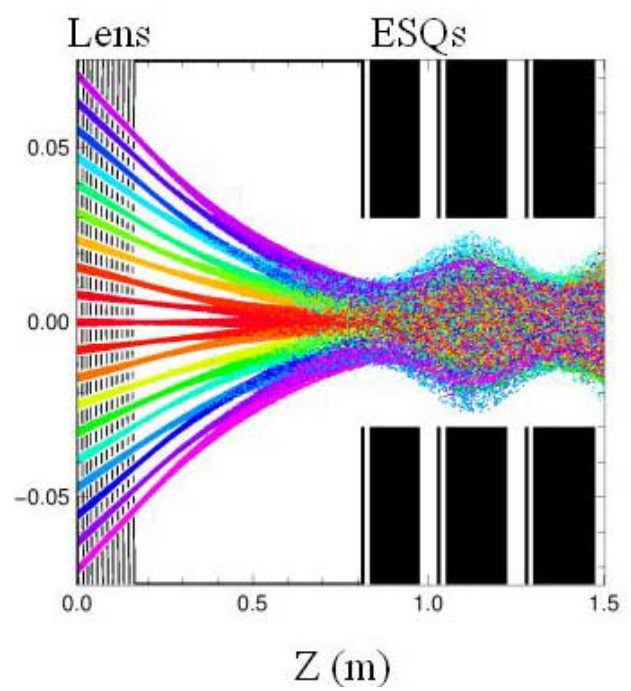

Figure 4 .Particle trajectories in $\mathrm{x}-\mathrm{z}$ space. The quadrupole fields in the experiment were different that what was used to generate the figure.

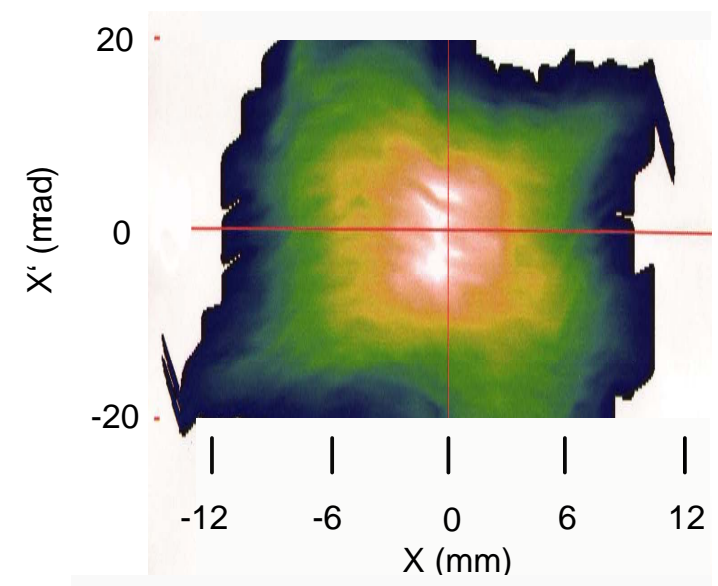

Figure 5. Optical measurement of $x-x^{\prime}$ phase space at 10 $\mathrm{cm}$ below the last quadrupole.

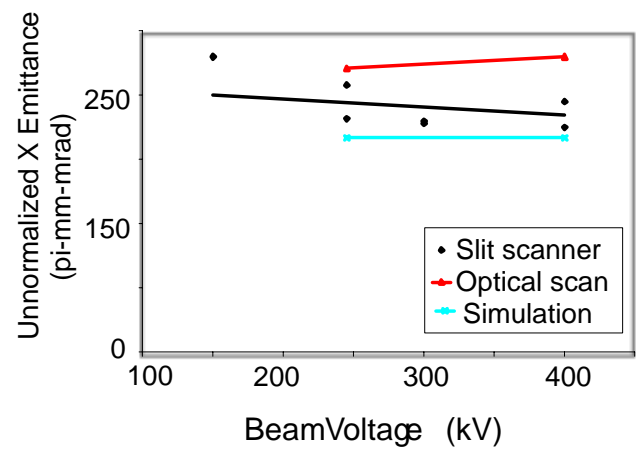

Figure 6: Comparison of the measured unnormalized $x$ emittance and the same emittance predicted by simulation.
The unnormalized emittance does not depend on the injector voltage if the perveance is held constant and the focusing fields are scaled to the beam voltage. The main contribution to the phase area was the "trapped" area when the beamlets were merged.

Figure 7 shows the beam current into the Faraday cup as a function of the beam voltage. The simulation beam current assumes a flat emitting meniscus. Higher current can be obtained at the expense of interior beam optics if the ion-emitting surface are allowed to bulge into the extraction gap by overdriving the RF plasma. At near 400 $\mathrm{kV}$ we believe that we were losing current from gas collision near the Faraday Cup. Obtaining good transport required that we operated near the correct perveance. At $400 \mathrm{kV}$ we measured $70 \mathrm{~mA}$ into the Faraday Cup.

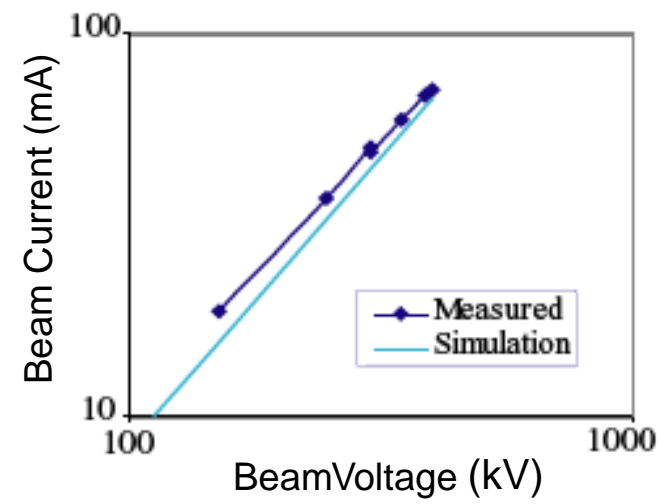

Figure 7. Beam current into Faraday Cup located after the ESQs.

\section{ACKNOWLEDGEMENTS}

We would like to thank Gary Freeze, Robert Hall, and Will Waldron for their assistance with the experiments.

\section{REFERENCES}

[1] D.P. Grote, E. Henestroza, J.W. Kwan, PRST Accelerators and Beams 6, 014202 (2003).

[2] J.W. Kwan, D.P. Grote and G.A. Westenskow, ”High Current Density Beamlets from a RF Argon Source for Heavy Ion Fusion Applications”, Rev. Sci. Instrum., 75, p1838, (2004).

[3] G.A. Westenskow, et al., "High Current Ion Source Development for Heavy Ion Fusion”, Proceedings of The Third International Conference on Inertial Fusion Sciences and Applications (IFSA2003), Monterey, California, September 7-12, 2003, p. 703.

[4] G.A. Westenskow, et al., "RF Plasma Source for a Heavy Ion Fusion Injector”, Nuc. Instr. \& Methods, in press. 